\title{
Fifty-kDa Hyaluronic Acid Upregulates Some Epidermal Genes without Changing TNF- $\alpha$ Expression in Reconstituted Epidermis
}

\author{
M. Farwick ${ }^{a} \quad$ G. Gauglitz ${ }^{b} \quad$ T. Pavicic $^{b} \quad$ T. Köhler ${ }^{a} \quad$ M. Wegmann ${ }^{a}$ \\ K. Schwach-Abdellaouid ${ }^{d} \quad$ B. Malle ${ }^{d}$ V. Tarabin ${ }^{c} \quad$ G.Schmitz ${ }^{c} \quad$ H.C. Korting ${ }^{b}$ \\ ${ }^{a}$ Evonik Goldschmidt GmbH, Essen, ${ }^{b}$ Department of Dermatology and Allergology, Ludwig Maximilians University, \\ Munich, and ' Institute for Clinical Chemistry and Laboratory Medicine, Universitätsklinikum Regensburg,

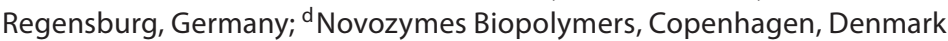

\section{Key Words}

Hyaluronic acid - Skin penetration - Anti-wrinkle effect •

Skin inflammation

\begin{abstract}
Background: Due to its strong water binding potential, hyaluronic acid (HA) is a well-known active ingredient for cosmetic applications. However, based on its varying molecular size, skin penetration of HA may be limited. Recent studies have demonstrated that low-molecular-weight HA (LMW HA) may show a certain proinflammatory activity. We thus aimed to characterize an LMW-sized HA molecule that combines strong anti-aging abilities with efficient skin penetration but lacks potential proinflammatory effects. Methods: Total RNA and total protein were isolated from reconstituted human epidermis following incubation with $\mathrm{HAs}$ of various molecular weights $(20,50,130,300,800$ and 1,500 kDa). Tumor necrosis factor- $\alpha$ expression was determined using quantitative PCR. Genomic and proteomic expression of various junctional proteins was determined using Affymetrix and common Western blotting techniques. Results: LMW HA of approximately $50 \mathrm{kDa}$ did not significantly alter tumor necrosis factor- $\alpha$ expression compared to $20-\mathrm{kDa} H \mathrm{H}$, but
\end{abstract}

\section{KARGER}

Fax +41613061234 E-Mail karger@karger.ch www.karger.com
(C) 2011 S. Karger AG, Basel

$1660-5527 / 11 / 0244-0210 \$ 38.00 / 0$

Accessible online at:

www.karger.com/spp revealed significantly higher skin penetration rates than larger sized HA associated with increased expression of genes and proteins known to be involved in tight junction formation and keratinocyte cohesion. Conclusion: LMW HA of approximately $50 \mathrm{kDa}$ shows better penetration abilities than larger-sized HA. In addition, LMW HA influences the expression of various genes including those contributing to keratinocyte differentiation and formation of intercellular tight junction complexes without showing proinflammatory activity. These observations contribute to current knowledge on the effects of LMW HA on keratinocyte biology and cutaneous physiology.

Copyright $\odot 2011$ S. Karger AG, Basel

\section{Introduction}

Hyaluronic acid (HA) represents a naturally occurring glycosaminoglycan biopolymer, located mostly in the intercellular matrix of the dermis but has also been found in the epidermal layer of the skin [1]. Its molecular structure

M.F. and G.G. contributed equally to the paper.
Hans C. Korting, MD

Department of Dermatology and Allergology, Ludwig Maximilians University Frauenlobstrasse 9-11

DE-80337 Munich (Germany)

Tel. +49 895160 6063, E-Mail HansChristian.Korting@med.uni-muenchen.de 
is highly conserved between mammalian species $[2,3]$. HA represents one of the major matrix substances in which cells and fibrous constituents of the dermal matrix including collagen and elastin are embedded [4]. Its invariant chemical structure reduces the likelihood of immunologic reactions, thus increasing its biocompatibility. HA molecules are also known to significantly contribute to the maintenance of the extracellular space. Due to their enormous water-binding capacity, HA molecules are highly relevant in controlling tissue hydration $[5,6]$. Additionally, HA seems to play a pivotal role in tissue regeneration since recent studies suggest that the integrity and balance of matrix components themselves, which undergo degradation and reconstruction, assure normal tissue function and contribute to the regulation of wound healing $[7,8]$. Besides being commonly utilized as an attractive therapeutic agent in medical fields such as ophthalmology and rheumatology, its extraordinary properties make HA a promising candidate for a variety of cosmetic applications, particularly in the context of skin regeneration, tissue augmentation and other anti-aging treatments [3]. However, this plethora of potential beneficial features is limited by the molecular size of HA, which can reach up to 2,000 $\mathrm{kDa}$, thus interfering with efficient skin penetration.

This phenomenon may easily be addressed by fragmentation of high-molecular-weight HA. However, recent studies have shown that low-molecular-weight (LMW) HA or HA fragments may be involved in various biological processes including cell proliferation, angiogenesis, migration, maturation, activation of protein tyrosine cascades and proinflammatory activity [9-11]. In a study by Voelcker et al. [12], HA fragments were recognized by so-called Toll-like receptors (TLRs) 2 and 4 on human melanoma cells leading to activation of these cells and thus production of proinflammatory mediators.

In the present study, we thus aimed to identify an LMW HA molecule that combines strong anti-aging and moisturizing abilities with efficient skin penetration but lacks the proinflammatory effects mediated by TLRs.

\section{Materials and Methods}

\section{Material}

HA was produced using a novel, solvent-free methodology based on a new fermentation strain of Bacillus subtilis. This fermentation process results in a protein-free HA with constant molecular weight that appears as a very fine powder after the process of spray drying.

LMW HA is produced by controlled thermal hydrolysis of high-molecular-weight HA. Briefly, the HA powder containing residual humidity is heated up to $120-130^{\circ} \mathrm{C}$ for different periods of time, and hydrolysis is performed under controlled conditions until specifications of viscosity are achieved.

\section{Methods}

In vitro Culturing of Reconstituted Human Epidermis

Constructs in the Presence of HA

Reconstituted human epidermis was purchased from SkinEthic (Nice, France) and incubated for $24 \mathrm{~h}$ in standard maintenance medium at $37^{\circ} \mathrm{C}$ and $5 \% \mathrm{CO}_{2}$ as previously described [13] before starting the experiments. In total, three different types of experiments employing reconstituted human epidermis constructs treated with various molecular weight forms of HA were conducted. In order to evaluate the possible proinflammatory effects of very LMW (VLMW) HA, the reconstituted human epidermis was incubated for $48 \mathrm{~h}$ with $50 \mu \mathrm{l}$ phosphate-buffered saline (PBS) containing $0.5 \%$ 20-, 50-, 130 - or $320-\mathrm{kDa} H A$, respectively. PBS-treated reconstituted human epidermis served as control. After incubation, RNA was isolated and served as template for cDNA generation. Using quantitative RT-PCR, the expression of the proinflammatory cytokine tumor necrosis factor$\alpha$ (TNF- $\alpha$ ) was determined.

Another set of experiments was performed to characterize the effects of HA on keratinocytes on a molecular level. In this context, reconstructed human epidermis was treated topically with $50 \mu \mathrm{l}$ of a thin liquid $\mathrm{O} / \mathrm{W}$ emulsion (composition: $3 \%$ glyceryl stearate-ceteth-20; $1 \%$ stearyl alcohol; $4 \%$ cetearyl ethylhexanoate; $4 \%$ caprylic/capric triglyceride; $\mathrm{pH}$ adjusted to 6 with $\mathrm{NaOH}$; water: ad. $100 \%$ ) containing $0.5 \%$ of $50-\mathrm{kDa} \mathrm{HA}$ and $800-\mathrm{kDa}$ $\mathrm{HA}, 0.2 \%$ retinol as positive control or not active at all as vehicle control. The emulsion type vehicle was chosen because retinol is insoluble in water. Retinol was dissolved in the oil phase, whereas HA was dissolved in the water phase. Following $48 \mathrm{~h}$ application, RNA was extracted for transcriptome analysis using microarray technique and TaqMan ${ }^{\circledR}$ RT-PCR assays (see below).

A third set of experiments using reconstituted human epidermis constructs was conducted in order to confirm some of the observations from the microarray study on the protein level. Therefore, the models were topically treated with 0.05 and $0.5 \%$ $50-\mathrm{kDa}$ HA (commercially available as HyaCare ${ }^{\circledR} 50$ ) dissolved in water for $72 \mathrm{~h}(\mathrm{n}=4)$. Afterwards, protein extracts were prepared and used for Western blotting analysis (see below).

In order to determine penetration properties of differentially sized HA molecules, diffusion of tritiated HA with a molecular weight of about 50,300, 800 or 1,500 kDa through dermatomed porcine ear skin was assessed using Franz diffusion cells as previously described [14]. In brief, full-thickness skin samples of visually intact skin from the ear of 5-month-old female domestic pigs were dermatomed to a thickness of about $750 \mu \mathrm{m}$ using an Acculan GA 643 (Aesculap, Tuttlingen, Germany). The samples were then mounted in modified Franz static dermal penetration cells with the external surface of the stratum corneum facing the donor chamber. After 5 and $22 \mathrm{~h}$ of HA application, the level of radioactivity in the receptor phase was determined and expressed as $\mathrm{ng} \cdot \mathrm{cm}^{-2} \cdot \mathrm{h}^{-1}$, which served as a parameter for skin penetration.

\section{RNA Isolation}

Total RNA was extracted from cultured skin constructs using RNeasy Mini Kit (Qiagen, Hilden, Germany) according to the manufacturer's recommendations. RNA concentration was assessed spectroscopically using SmartSpec Plus (Biorad, München, 
Germany). Purity and integrity of the RNA was determined by an Agilent 2100 bioanalyzer with a 6000 Nano LabChip reagent set (Agilent Technologies, Santa Clara, Calif., USA). RNA samples were stored at $-80^{\circ} \mathrm{C}$ until analysis.

\section{Quantitative RT-PCR}

Reverse transcription was performed using the First-Strand cDNA Synthesis Kit (Super Script III, Invitrogen, Life Technologies, Carlsbad, Calif., USA) according to the guidelines of the manufacturer starting with $100 \mathrm{ng}$ purified RNA from each sample. Quantitative PCR was carried out with an Opticon DNA engine (MJ Research, Waltham, Mass., USA) using SYBR Green PCR Master Mix (Applied Biosystems, Darmstadt, Germany) according to the manufacturer's instructions. The following genespecific primers were used for TNF- $\alpha$ : forward $5^{\prime}$-CTG TGG CCC AGG CAG TCA GA-3' and reverse 5'-GGC GTT TGG GAA GGT TGG AT-3'. Glycerin aldehyde phosphate dehydrogenase (GAPDH) served as a housekeeping gene with the following primer pair: forward 5'-ACC ACA GTC CAT GCC ATC AC-3' and reverse 5'-TCC ACC ACC CTG TTG CTG TA-3'.

DNA Microarray and Data Analysis

Gene expression profiles were determined using Affymetrix HGU133 plus 2.0 GeneChips (Affymetrix, Santa Clara, Calif., USA) using $2 \mu \mathrm{g}$ of total RNA pooled from three reconstituted human epidermis skin models. Gene chip assays and initial analysis were carried out as previously described [15].

\section{TaqMan RT-PCR Assays}

TaqMan first-strand cDNA synthesis was performed with the reverse transcription system from Promega (Madison, Wisc., USA) according to the manufacturer's instructions. Real-time RT-PCR analysis was performed with an ABI7900HT machine (Applied Biosystems). All reagents necessary for running TaqMan RT-PCR assays, including primers and probes were purchased from Applied Biosystems and used according to the manufacturer's instructions. TaqMan analysis of transcripts for CALB1 (Hs01077193_m1), CLDN4 (Hs00533616_s1), CLDN7 (Hs00600772_m1), CLDN17 (Hs00273276_s1), OCLN (Hs00170162_m1), TJP2 (Hs00178081_m1) and 18S-rRNA (Hs99999901_s1) as endogenous control, was performed with predesigned and optimized Assays on Demand (Applied Biosystems). The reaction parameters were as follows: $2 \mathrm{~min} 50^{\circ} \mathrm{C}$ hold, $10 \mathrm{~min} 95^{\circ} \mathrm{C}$ hold, followed by 40 cycles of $10 \mathrm{~s} 95^{\circ} \mathrm{C}$ melt and $1 \mathrm{~min} 60^{\circ} \mathrm{C}$ annealing and extension. Measurements were performed in triplicate for both donors. Results were analyzed with an ABI sequence detector software version 2.0 (Applied Biosystems). Relative quantification was performed using $18 \mathrm{~S}-\mathrm{rRNA}$ as reference as described earlier [16].

\section{Western Blotting}

In order to confirm the observed genomic changes on a protein level, reconstructed human epidermis models (SkinEthic) were topically treated with 0.05 and $0.5 \% 50-\mathrm{kDa} \mathrm{HA}$ for $72 \mathrm{~h}$ $(n=4)$. Then, proteins were extracted using standard protocols and $20 \mu \mathrm{g}$ of the resulting supernatant was run out on a $4-20 \%$ SDS-polyacrylamide gel and subsequently electrotransferred to immune-blot PVDF membranes (Bio-Rad Laboratories, Hercules, Calif., USA). PVDF membrane sheets were then probed with primary antibody against tight junction protein-1 (TJP-1; BD Bio-

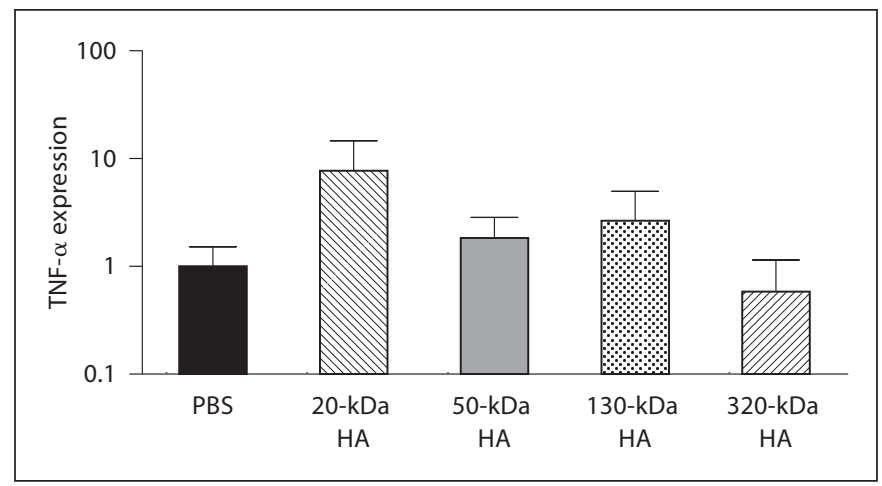

Fig. 1. VLMW HA is associated with an increased proinflammatory response. Total RNA was isolated from reconstituted human epidermis following incubation with PBS or HA of various molecular weights for $48 \mathrm{~h}$. TNF- $\alpha$ expression was determined using quantitative RT-PCR with GAPDH serving as endogenous control. Mean value of the target was divided by the mean value of the endogenous control to obtain a normalized mean quantity per sample. Results shown represent $n=3$ per group, as indicated in the main text. Bars represent means, error bars correspond to SEM.

science, Franklin Lake, N.J., USA), tight junction protein-2 (TJP2; Santa Cruz Biotechnology, Calif., USA), E-cadherin (BD Bioscience), $\beta$-catenin (BD Bioscience), occludin (Santa Cruz Biotechnology), claudin-4 (Santa Cruz Biotechnology), claudin-17 (Abcam, Cambridge, Mass., USA), claudin-1 (Santa Cruz Biotechnology) and GAPDH (Abcam). The signals were then detected using horseradish peroxidase-conjugated secondary antibody, developed with chemiluminescent substrates (Pierce Biotechnology, Rockford, Ill., USA) and were quantified with a density scan (Lumi-Imager ${ }^{\mathrm{TM}}$ F1, Roche Diagnostics, Mannheim, Germany). After quantification, the intensities of the protein signals were normalized to the respective GAPDH signals.

\section{Statistical Analysis}

Results are presented as mean \pm SEM ( $n=3$ per group, at each time point, if not stated differently). The data were analyzed using one-way ANOVA and Kruskal-Wallis test, and differences were considered significant at a $\mathrm{p}$ value of $<0.05$.

\section{Results}

\section{VLMW HA Is Associated with an Increased Proinflammatory Response}

VLMW HA with a molecular weight of $20 \mathrm{kDa}$ revealed markedly increased expression of TNF- $\alpha$ (7.7 \pm 6.9) in reconstructed epidermis models compared to models treated with PBS or HA molecules of higher molecular weight $(1 \pm 0.5 ; 1.8 \pm 1.0 ; 2.7 \pm 2.3$ and $0.58 \pm$ 0.6 , HA 50, 130 and $320 \mathrm{kDa}$, respectively), indicating a proinflammatory effect of VLMW HA (fig. 1). In con- 


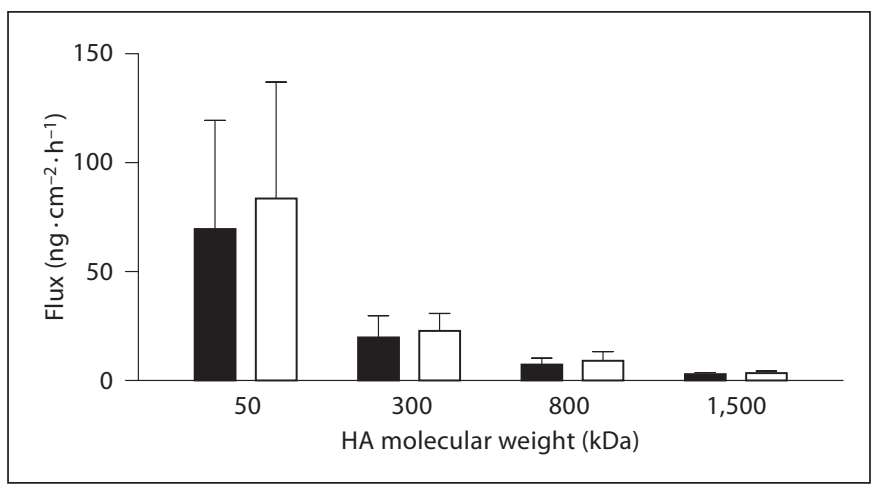

Fig. 2. LMW HA reveals improved penetrating properties compared to HA with higher molecular weights. HA molecules with different molecular weights, namely 50, 300, 800 and $1,500 \mathrm{kDa}$, were tested for their ability to penetrate pig ear skin (expressed in $\mathrm{ng} \cdot \mathrm{cm}^{-2} \cdot \mathrm{h}^{-1}$ ) following $5(\square)$ and $22 \mathrm{~h}(\square)$ of HA incubation. Results shown represent $n=3$ per group, as indicated in the main text. Bars represent means, error bars correspond to SEM.

trast, HA molecules with a molecular weight $>50 \mathrm{kDa}$ did not induce marked upregulation of TNF- $\alpha$ expression compared to controls (fig. 1).

\section{LMW HA Reveals Improved Penetration \\ Properties Compared to HA with a Molecular \\ Weight of $>300 \mathrm{kDa}$}

HA molecules with different molecular weight, namely $50,300,800$ and $1,500 \mathrm{kDa}$, were tested for their ability to penetrate pig ear skin after 5 and $22 \mathrm{~h}$ of HA application. As shown in figure 2, only small amounts of HA with a molecular weight of $300 \mathrm{kDa}$ and more $(19.8$ \pm 10 and $22.8 \pm 8 ; 7.3 \pm 3$ and $9.1 \pm 4.2 ; 2.9 \pm 0.8$ and $3.4 \pm 1 \mathrm{ng} \cdot \mathrm{cm}^{-2} \cdot \mathrm{h}^{-1}$; HA 300,800 and $1,500 \mathrm{kDa}$, respectively) penetrated the skin, as seen at 5 and $22 \mathrm{~h}$ of incubation. In contrast, LMW HA with only $50 \mathrm{kDa}$ revealed markedly higher skin penetration compared to the one with $300-\mathrm{kDa} H A(69.5 \pm 49.9$ and $83.5 \pm 53.4$ $\mathrm{ng} \cdot \mathrm{cm}^{-2} \cdot \mathrm{h}^{-1}$; fig. 2). Within duration ( $5 \mathrm{vs.} 22 \mathrm{~h}$ ) of incubation, the flux of HA remained constant over time.

\section{LMW HA Is Associated with Increased Expression of Genes Known to Be Involved in Keratinocyte \\ Differentiation and Cohesion}

LMW HA with a molecular size of $50 \mathrm{kDa}$ markedly affected up- or downregulation of about 120 genes (data not shown) including key genes involved in keratinocyte regulation as well as genes that play important roles for their cohesion. In contrast, HA with a molecular weight
Table 1. Effects of LMW HA with $50 \mathrm{kDa}$ and HA with a molecular weight of $800 \mathrm{kDA}$ on gene expression in reconstructed epidermis: microarray analysis

Fold change vs. vehicle

HA $50 \mathrm{kDa}$ HA $800 \mathrm{kDa}$

\section{Junctional control}

Occludin

Claudin-4

Claudin-7

Claudin-17

Aquaporin-3

Desmocollin-2

TJP-2

Striatin, calmodulin-binding protein

Kinesin family member C3

Differentiation/epidermis development

Kallikrein-6

Kallikrein-14

Repetin

Keratin-34

Forkhead box Q1

ATPase, $\mathrm{Ca}^{2+}$ transporting, type $2 \mathrm{C}$, member $1-2.2$

Ceramide kinase

Small proline-rich protein-4

Biliverdin reductase A

Mitogen-activated protein kinase kinase-

Calbindin-1

S100 calcium-binding protein A12

(calgranulin C)

$3.4 \quad 2.0$

$3.8 \quad 2.4$

$\begin{array}{ll}3.8 & 2.4 \\ 7.5 & 2.8 \\ 5.1 & 3.2\end{array}$

$5.1 \quad 3.2$

$2.3-2.0$

$1.8 \quad 1.4$

$1.9-1.3$

$2.2 \quad 1.5$

$2.6-1.8$

Others

Thrombospondin-1

Sirtuin

TIMP metallopeptidase inhibitor-3

Glutathione peroxidase-2

Heparin-binding EGF-like growth factor

Interleukin-10 receptor- $\beta$

Interleukin-18

$3.8 \quad 3.3$

$2.0 \quad 2.1$

$\begin{array}{ll}2.0 & 2.1 \\ 4.6 & 2.3\end{array}$

$3.0 \quad 1.4$

$4.0-3.2$

$-2.2-1.6$

$-2.5-2.0$

$2.7 \quad 2.2$

$-1.9-1.3$

$2.1 \quad 1.5$

$11.3 \quad 4.4$

$2.0 \quad 1.6$

$\begin{array}{ll}3.0 & 2.6\end{array}$

$2.9 \quad 1.6$

$2.2-1.8$

$3.3 \quad 2.7$

$3.4 \quad 2.2$

$-2.7-2.0$

$-1.8-1.9$

of about $800 \mathrm{kDa}$ only led to differential expression of 40 genes (data not shown). A selection of up- or downregulated genes and their associated functions is presented in table 1.

In particular, incubation of reconstructed human epidermis with $50-\mathrm{kDa} \mathrm{HA}$ for $48 \mathrm{~h}$ resulted in marked upregulation of calbindin- 1 , occludin, claudin- $4,-7$, and -17 , TJP-2 compared to vehicle treatment (table 1). Notably, upregulation of all these genes was less pronounced in the case of $800-\mathrm{kDa} \mathrm{HA}$ (table 1).

Due to the fact that RNA pooled from 3 biological replicates was used for microarray studies, the obtained results were judged as an indication that tight junction control is modulated by application of $50-\mathrm{kDa}$ HA. For further verification, the results for selected targets were 


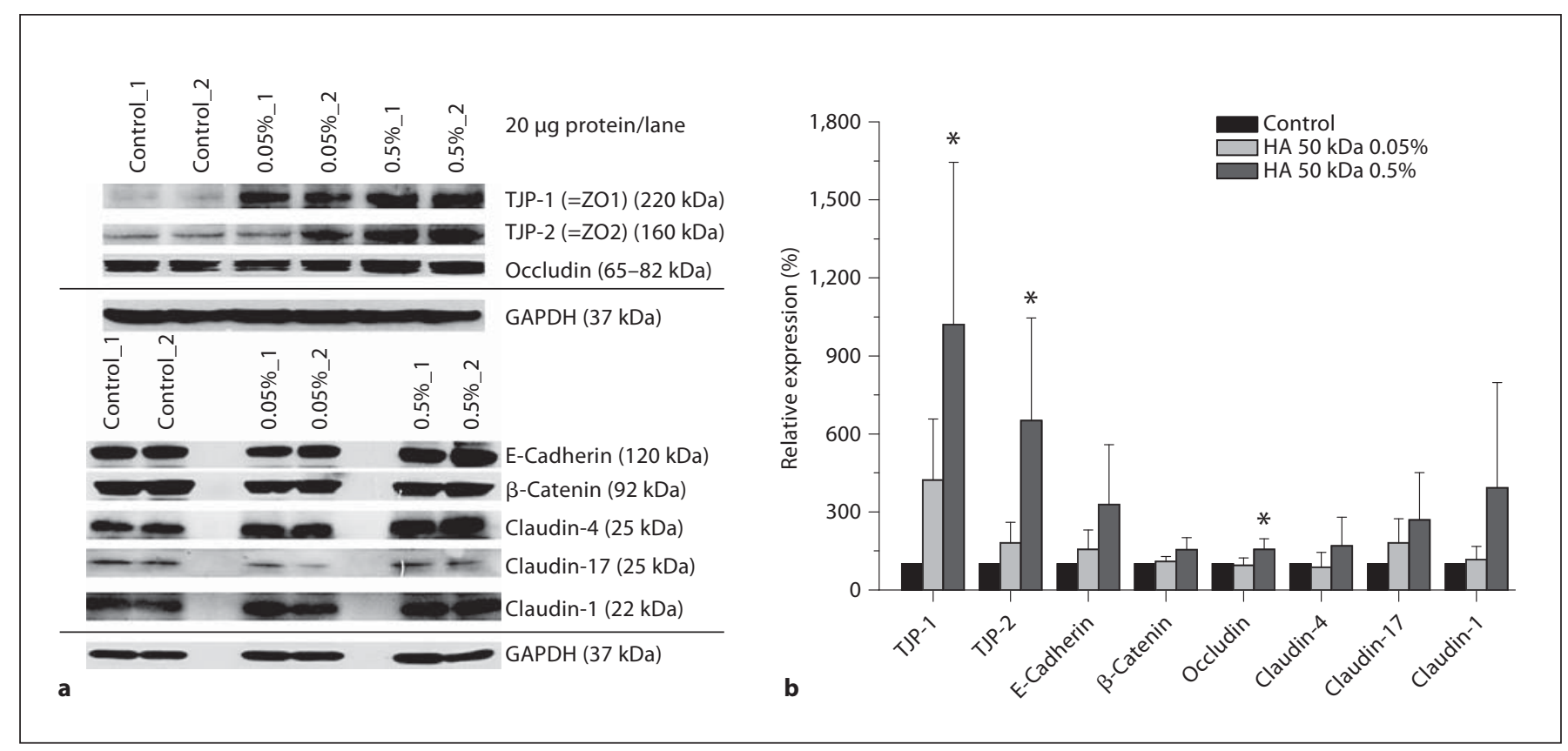

Fig. 3. a LMW HA is associated with increased expression of proteins known to be involved in keratinocyte regulation and cohesion. Accumulation of TJP-1, TJP-2, claudin-1, -4 and -17 as well as E-cadherin, $\beta$-catenin and occludin was determined in reconstituted human epidermis harvested after $72 \mathrm{~h}$ of topical treatment with either 0.05 or $0.5 \% 50-\mathrm{kDa}$ HA. b Histograms depict intensities of the phosphorylated protein bands divided by the total form of the respective protein $(n=4)$. Bars represent means, error bars correspond to SEM. ${ }^{*} \mathrm{p}<$ 0.05 , statistical significance for every comparison between groups.

Table 2. Effects of LMW HA with $50 \mathrm{kDa}$ and HA with a molecular weight of $800 \mathrm{kDA}$ on gene expression in reconstructed epidermis: qRT-PCR analysis

\begin{tabular}{llllll}
\hline Target & \multicolumn{2}{l}{$\mathrm{HA} 50 \mathrm{kDa}$} & & \multicolumn{2}{l}{$\mathrm{HA} 800 \mathrm{kDa}$} \\
\cline { 2 - 3 } \cline { 5 - 6 } & $\begin{array}{l}\text { fold change } \\
\text { vs. vehicle }\end{array}$ & $\begin{array}{l}\mathrm{SD} / \mathrm{p} \\
\text { value }\end{array}$ & & $\begin{array}{l}\text { fold change } \mathrm{SD} / \mathrm{p} \\
\text { vs. vehicle } \\
\text { value }\end{array}$ \\
\hline Calbindin-1 & 5.1 & $0.28 / 0.00$ & & 1.2 & $1.41 / 0.64$ \\
Claudin-4 & 3.0 & $0.27 / 0.01$ & & 3.2 & $0.42 / 0.04$ \\
Claudin-7 & 6.1 & $0.41 / 0.01$ & & 2.1 & $0.44 / 0.06$ \\
Claudin-17 & 3.7 & $0.52 / 0.04$ & & 2.2 & $0.45 / 0.14$ \\
TJP-2 & 1.5 & $0.92 / 0.06$ & & 1.3 & $0.22 / 0.01$ \\
Occludin & 1.1 & $0.19 / 0.01$ & & 0.8 & $0.25 / 0.10$ \\
\hline
\end{tabular}

reproduced independently by quantitative real-time PCR (qRT-PCR) experiments, in this case without pooling and including statistical analysis. Results are shown in table 2 . In general, the qRT-PCR experiments confirmed the previous microarray results. With the exception of the occludin gene, all genes were upregulated by treatment with $50-$ or $800-\mathrm{kDa} \mathrm{HA}$, and the effects were gen- erally more pronounced in case of $50-\mathrm{kDa} \mathrm{HA}$. All genes except the one encoding TJP-2 proved significantly ( $\mathrm{p} \leq$ 0.05 ) upregulated by $50-\mathrm{kDa} \mathrm{HA}$.

\section{LMW HA Is Associated with Increased Expression of Proteins Known to Be Involved in Keratinocyte Differentiation and Cohesion}

In order to confirm the superior stimulatory effects of $50-\mathrm{kDa} \mathrm{HA}$ on gene expression also on the protein level, we conducted a series of Western blotting experiments. Treatment of human epidermis models with 50$\mathrm{kDa} \mathrm{HA}$ resulted in increased protein levels of a number of TJPs in a dose-dependent manner. Specifically, TJP1 and TJP2 were found to be markedly increased after 72hour posttreatment. The observed increase was accompanied by induction of claudin-1, -4 and -17 as well as E-cadherin, $\beta$-catenin and occludin (fig. 3). However, while incubation of human epidermis with $0.5 \% 50-\mathrm{kDa}$ HA led to significant upregulation of TJP1, TJP2 and occludin, treatment with $0.05 \% 50-\mathrm{kDa} \mathrm{HA}$ did not significantly alter the amount of the respective proteins (fig. 3). 


\section{Discussion}

HA, first discovered in the vitreous humor of the eye in 1934 [17] and subsequently synthesized in vitro in 1964 [18], consists of a basic unit of two sugars, glucuronic acid and $\mathrm{N}$-acetylglucosamine, polymerized into large macromolecules of over 30,000 repeating units [3]. Due to its enormous water-binding capacity and its beneficial effects on cell proliferation, migration and thus tissue regeneration, HA has recently gained prominence in rejuvenative medicine as the injectable dermal filler of choice for the treatment of cutaneous lines and wrinkles [3]. However, applicability and potential beneficial activity features of HA have been shown to be limited by the molecular size of HA, which may reach up to $2,000 \mathrm{kDa}$ and thus may interfere with efficient skin penetration. In contrast, VLMW HA or HA fragments may be recognized by so-called TLRs potentially leading to production of proinflammatory mediators [12]. At sites of inflammation, HA molecules undergo rapid degradation due to massive production of hyaluronidases by infiltrating inflammatory cells and bacterial invaders [19]. These HA fragments have been implicated in the process of injury and repair since they have been shown to activate inflammatory cells such as macrophages and dendritic cells to express proinflammatory mediators and enzymes degrading extracellular matrix [20-23]. Recent studies identified TLR-4 as the HA fragment binding receptor that links HA degradation and activation of inflammatory cells $[24,25]$. In this study, we thus aimed to characterize an LMW-sized HA molecule that combines strong antiaging and moisturizing abilities with efficient skin penetration but misses the proinflammatory effects mediated by TRLs. By measuring TNF- $\alpha$ expression in reconstituted human epidermis after incubation with variedly sized LMW HA, we found that VLMW HA with a molecular weight of around $20 \mathrm{kDa}$ led to marked upregulation of TNF- $\alpha$ expression in keratinocytes, indicating an inductive effect on the inflammatory response. In contrast, HA molecules with a molecular weight of $50 \mathrm{kDa}$ or more did not alter the TNF- $\alpha$ expression profile in these cells to a large extent. However, differences in TNF$\alpha$ expression may be due to penetration differences of the variedly sized HA molecules applied to the reconstituted human epidermis.

Having shown that HA with a molecular weight of 50 $\mathrm{kDa}$ and higher did not reveal proinflammatory activity in keratinocytes, we tested the penetrating properties of variedly sized LMW HA, namely 50, 300, 800 and 1,500 $\mathrm{kDa}$. It was observed that a significantly higher skin pen- etration of $50-\mathrm{kDa} \mathrm{HA}$ molecules occurs compared to the ones with a molecular weight of $300-\mathrm{kDa} \mathrm{HA}$ and above. This indicates a relevant dependence of percutaneous transport on the HA molecular weight with a better permeation apparent for the lower-molecular-weight fractions. The route for this penetration is unknown, but as the molecular weight is much too high for percutaneous absorption, a follicular route is highly likely. Various skin delivery systems have been discussed [26]. Recent results on follicular penetration obtained at the Center for Experimental and Applied Cutaneous Physiology, Charité - Universitätsmedizin Berlin, Germany, emphasize that the hair follicles represent a highly relevant and efficient penetration pathway and reservoir for topically applied substances [27]. It has been demonstrated that the penetration depth of the particles can be influenced by their size resulting in the possibility of a differentiated targeting of specific follicular structures. In vitro measurements on pig ear skin appear to be equal or even superior for the analysis of follicular penetration, as compared to in vitro investigations on excised human skin indicating the suitability of this porcine tissue as a model for human skin $[28,29]$.

Having identified the smallest molecular size of HA that does not induce an inflammatory response but shows the best bioavailability within the range analyzed, we next aimed to characterize the molecular impact of a LMW HA of about $50 \mathrm{kDa}$ on keratinocytes in comparison to a HA molecule with a molecular weight of 800 $\mathrm{kDa}$, which is a representation of the commonly utilized $\mathrm{HA}$ used as active ingredient in cosmetic preparations for years. Using transcriptome analysis, we found that incubation of keratinocytes with LMW HA significantly affected overall up- or downregulation of about 120 genes, in particular genes known to be involved in keratinocyte regulation as well as genes that play important roles for their cohesion. HA with a molecular weight of about 800 $\mathrm{kDa}$, in contrast, only induced differential expression of 40 genes, whereas topical application of $0.5 \%$ retinol under the same conditions changed the expression of about 160 genes (data not shown). These findings demonstrate the high gene regulatory potential of LMW HA. The treatment specifically led to marked upregulation of a broad variety of different TJPs on a genomic and proteomic level. TJPs comprise a novel group of integral membrane proteins necessary for cell-to-cell contacts and responsible for the barrier function in epithelial and endothelial cells in various tissues. The tight junction membrane domain contains at least three distinct proteins, named occludin, claudin and junctional adhesion 
molecule, all of which have been discussed to contribute to keratinocyte differentiation and formation of intercellular tight junction complexes [30, 31].

The data obtained in our in vitro experiments suggest that the novel LMW HA may be associated with better anti-wrinkle properties in contrast to high-molecularweight HA based on improved skin penetration. Clinical data elucidating the clinical effects of topically applied HA of differing molecular weight support our hypothesis (data not published yet). HA is a substance with various physiological functions in different cell and tissue types. Clearly, one of its major functions in skin is to constitute the structural backbone of the dermal extracellular matrix promoting proper tissue architecture. Secondly, it binds large amounts of water, thereby keeping the dermal skin layer properly moisturized. Apart from these wellcharacterized functions, a growing number of studies suggest that HA also participates in different cellular functions, including regulation of metabolite diffusion, cell migration, cell signaling, cell proliferation and differentiation, wound healing, cell adhesion, angiogenesis and inflammation [32]. Although the largest amount of skin HA is present in the dermis, significant amounts could also be detected in the epidermis, in particular in the upper spinous and granular layers [33-35], but also in the stratum corneum [36]. It is assumed that HA contributes to maintenance of epidermal skin hydration. Other functions of epidermal HA might include regulation of cell mitosis (basal layer) as well as recruitment of Langerhans cells via their CD44 receptors $[37,38]$ and wound healing/regeneration processes [34]. Notably, HA levels were found to be greatly reduced in aged epidermis, but not in aged dermis. This age-related epidermal HA deficiency might be compensated by topical delivery via cosmetic formulations containing $\mathrm{HA}$.

\section{Conclusions}

Beneficial features of HA may be related to particular molecular sizes. We found that an LMW HA of approximately $50 \mathrm{kDa}$ penetrates the skin better than largersized HA and, accordingly, influences the expression of many genes including those contributing to keratinocyte differentiation and formation of intercellular tight junction complexes which are reported to be reduced in aged and photodamaged skin. This can be utilized without running the risk of increased proinflammatory activity.

\section{Acknowledgements}

This study was funded by Evonik Goldschmidt, Essen, Germany, and by Novozymes Biopolymers, Copenhagen, Denmark.

\section{References}

1 Brown MB, Jones SA: Hyaluronic acid: a unique topical vehicle for the localized delivery of drugs to the skin. J Eur Acad Dermatol 2005; 19:308-318.

2 Kielty CM, Whittaker SP, Grant ME, Shuttleworth CA: Type VI collagen microfibrils: evidence for a structural association with hyaluronan. J Cell Biol 1992;118:979-990.

3 Price RD, Berry MG, Navsaria HA: Hyaluronic acid: the scientific and clinical evidence. J Plast Reconstr Aesthet Surg 2007;60: 1110-1119.

4 Baccarani-Contri M, Vincenzi D, Cicchetti F, Mori G, Pasquali-Ronchetti I: Immunocytochemical localization of proteoglycans within normal elastin fibers. Eur J Cell Biol 1990;53:305-312.

5 Cleland RL, Wang JL: Ionic polysaccharides. 3. Dilute solution properties of hyaluronic acid fractions. Biopolymers 1970;9:799-810.

6 Bhattacharya J, Cruz T, Bhattacharya S, Bray BA: Hyaluronan affects extravascular water in lungs of unanesthetized rabbits. J Appl Physiol 1989;66:2595-2599.
7 Weindl G, Schaller M, Schafer-Korting M, Korting HC: Hyaluronic acid in the treatment and prevention of skin diseases: molecular biological, pharmaceutical and clinical aspects. Skin Pharmacol Physiol 2004;17: 207-213.

8 Turino GM: The lung parenchyma - a dynamic matrix. J. Burns Amberson lecture. Am Rev Respir Dis 1985;132:1324-1334.

9 Fieber C, Baumann P, Vallon R, et al: Hyaluronan-oligosaccharide-induced transcription of metalloproteases. J Cell Sci 2004;117: 359-367.

10 Taylor KR, Trowbridge JM, Rudisill JA, Termeer CC, Simon JC, Gallo RL: Hyaluronan fragments stimulate endothelial recognition of injury through TLR4. J Biol Chem 2004; 279:17079-17084.

11 Termeer C, Benedix F, Sleeman J, et al: Oligosaccharides of hyaluronan activate dendritic cells via toll-like receptor 4. J Exp Med 2002;195:99-111.
12 Voelcker V, Gebhardt C, Averbeck M, et al: Hyaluronan fragments induce cytokine and metalloprotease upregulation in human melanoma cells in part by signalling via TLR4. Exp Dermatol 2008;17:100-107.

13 Mehul B, Asselineau D, Bernard D, et al: Gene expression profiles of three different models of reconstructed human epidermis and classical cultures of keratinocytes using cDNA arrays. Arch Dermatol Res 2004;296: 145-156.

14 Gamer AO, Leibold E, van Ravenzwaay B: The in vitro absorption of microfine zinc oxide and titanium dioxide through porcine skin. Toxicol In Vitro 2006;20:301-307.

15 Langmann T, Moehle C, Mauerer R, et al: Loss of detoxification in inflammatory bowel disease: dysregulation of pregnane $\mathrm{X}$ receptor target genes. Gastroenterology 2004; 127:26-40.

16 Langmann T, Mauerer R, Zahn A, et al: Realtime reverse transcription-PCR expression profiling of the complete human ATP-binding cassette transporter superfamily in various tissues. Clin Chem 2003;49:230-238. 
17 Weigel PH, Frost SJ, LeBoeuf RD, McGary CT: The specific interaction between fibrin(ogen) and hyaluronan: possible consequences in haemostasis, inflammation and wound healing. Ciba Found Symp 1989;143: 248-261, discussion 261-244, 281-245.

18 Schiller S: Synthesis of hyaluronic acid by a soluble enzyme system from mammalian tissue. Biochem Biophys Res Commun 1964; 15:250-255.

19 Girish KS, Kemparaju K: The magic glue hyaluronan and its eraser hyaluronidase: a biological overview. Life Sci 2007;80:1921-1943.

20 Chen WYJ, Abatangelo G: Functions of hyaluronan in wound repair. Wound Repair Regen 1999;7:79-89.

21 Noble PW, Lake FR, Henson PM, Riches DWH: Hyaluronate activation of CD44 induces insulin-like growth factor-I expression by a tumor-necrosis-factor-alpha dependent mechanism in murine macrophages. J Clin Invest 1993;91:2368-2377.

22 McKee CM, Penno MB, Cowman M, et al: Hyaluronan (HA) fragments induce chemokine gene expression in alveolar macrophages - the role of HA size and CD44. J Clin Invest 1996;98:2403-2413.

23 Noble PW, McKee CM, Horton MR: Induction of inflammatory gene expression by low-molecular-weight hyaluronan fragments in macrophages. Wenn Gr Int 1998; $72: 219-225$
24 Taylor KR, Trowbridge JM, Rudisill JA, Termeer CC, Simon JC, Gallo RL: Hyaluronan fragments stimulate endothelial recognition of injury through TLR4. J Biol Chem 2004; 279:17079-17084.

25 Voelcker V, Gebhardt C, Averbeck M, et al: Hyaluronan fragments induce cytokine and metalloprotease upregulation in human melanoma cells in part by signalling via TLR4. Exp Dermatol 2008;17:100-107.

26 Menon GK, Brandsma JL, Schwartz PM: Particle-mediated gene delivery and human skin: ultrastructural observations on stratum corneum barrier structures. Skin Pharmacol Phys 2007;20:141-147.

27 Lademann J, Knorr F, Richter H, et al: Hair follicles - an efficient storage and penetration pathway for topically applied substances. Skin Pharmacol Phys 2008;21:150-155.

28 Lademann J, Richter H, Meinke M, Sterry W, Patzelt A: Which skin model is the most appropriate for the investigation of topically applied substances into the hair follicles? Skin Pharmacol Phys 2010;23:47-52.

29 Jacobi U, Kaiser M, Toll R, et al: Porcine ear skin: an in vitro model for human skin. Skin Res Technol 2007;13:19-24.

30 Telgenhoff D, Ramsay S, Hilz S, Slusarewicz P, Shroot B: Claudin 2 mRNA and protein are present in human keratinocytes and may be regulated by all-trans-retinoic acid. Skin Pharmacol Phys 2008;21:211-217.
31 Tebbe B, Mankertz J, Schwarz C, et al: Tight junction proteins: a novel class of integral membrane proteins - expression in human epidermis and in $\mathrm{HaCaT}$ keratinocytes. Arch Dermatol Res 2002;294:14-18.

32 Stern R, Maibach HI: Hyaluronan in skin: aspects of aging and its pharmacologic modulation. Clin Dermatol 2008;26:106-122.

33 Bertheim U, Hellstrom S: The distribution of hyaluronan in human skin and mature, hypertrophic and keloid scars. Br J Plast Surg 1994;47:483-489.

34 Tammi R, Pasonen-Seppanen S, Kolehmainen E, Tammi M: Hyaluronan synthase induction and hyaluronan accumulation in mouse epidermis following skin injury. J Invest Dermatol 2005;124:898-905.

35 Wang C, Tammi M, Tammi R: Distribution of hyaluronan and its CD44 receptor in the epithelia of human skin appendages. Histochemistry 1992;98:105-112.

36 Sakai S, Yasuda R, Sayo T, Ishikawa O, Inoue $S$ : Hyaluronan exists in the normal stratum corneum. J Invest Dermatol 2000;114:11841187.

37 Weiss JM, Renkl AC, Sleeman J, et al: CD44 variant isoforms are essential for the function of epidermal Langerhans cells and dendritic cells. Cell Adhes Commun 1998;6: 157-160.

38 Weiss JM, Sleeman J, Renkl AC, et al: An essential role for CD44 variant isoforms in epidermal Langerhans cell and blood dendritic cell function. J Cell Biol 1997;137:1137-1147. 